NOTE

\title{
Morbilliviral encephalitis in a striped dolphin Stenella coeruleoalba calf from Italy
}

\author{
Giovanni Di Guardo ${ }^{1, *}$, Cristiano Cocumelli ${ }^{2}$, Francesco Scholl ${ }^{2}$, \\ Cristina Esmeralda Di Francesco ${ }^{1}$, Roberto Speranza ${ }^{1}$, Massimiliano Pennelli ${ }^{1}$, \\ Claudia Eleni ${ }^{2}$
}

\author{
${ }^{1}$ Faculty of Veterinary Medicine, Department of Comparative Biomedical Sciences, University of Teramo, \\ Piazza Aldo Moro 45, 64100 Teramo, Italy
}

${ }^{2}$ Istituto Zooprofilattico Sperimentale delle Regioni Lazio e Toscana, Via Appia Nuova 1411, 00178 Rome, Italy

\begin{abstract}
A free-living, striped dolphin Stenella coeruleoalba calf was stranded on the Latium coast of Italy in November 2009. Significant neuropathological findings included non-suppurative meningoencephalitis, microgliosis, neuronal degeneration, astrocytosis, and occasional multinucleate syncytia. Immunohistochemistry (IHC) and reverse transcription polymerase chain reaction (RTPCR) for Morbillivirus were positive exclusively from the brain, with morbilliviral antigen and nucleic acid being detected in neurons and, to a lesser extent, in astrocytes. A low neutralizing antibody titer (1:10) against Morbillivirus (Canine distemper virus, CDV) was also found in blood serum, with no simultaneous presence of serum antibodies to Brucella spp. or Toxoplasma gondii. Furthermore, no pathogenic bacteria were isolated from any tissue or biological sample. This is the second report of morbilliviral encephalitis in a striped dolphin stranded along the Italian coastline in a $16 \mathrm{yr}$ period (1993 to 2009). The neurohistopathological, IHC, and biomolecular features of this case are of additional interest, as antigenic and genomic positivity were exclusively confined to the brain of this dolphin, which may have acquired morbilliviral infection either postnatally or transplacentally.
\end{abstract}

KEY WORDS: Encephalitis · Dolphin morbillivirus · Striped dolphin · Italy · Mediterranean Sea

\section{INTRODUCTION}

Morbilliviruses have been recognized, for more than $20 \mathrm{yr}$, as biologic disease agents of great concern for free-ranging cetaceans (Van Bressem et al. 2009). This is also true for Toxoplasma gondii and Brucella spp., 2 additional neurotropic pathogens that are of particular relevance in striped dolphins Stenella coeruleoalba (Domingo et al. 1992, González et al. 2002, HernándezMora et al. 2008, Di Guardo et al. 2010).

Between the end of 2006 and the beginning of 2007, a Morbillivirus epidemic was reported in pilot whales Globicephala melas around the Strait of Gibraltar (Fernández et al. 2008) and, in the following months, in striped dolphins and pilot whales along the Spanish Mediterranean coast (Raga et al. 2008). Apart from the milder mortality rate $(\sim 60$ pilot whales and $\sim 200$ striped dolphins), this outbreak shares many similarities with the mass die-off of striped dolphins (estimated to have been many hundreds, if not thousands) that occurred from 1990 to 1992 in the Mediterranean Sea and that was caused by a newly identified agent, Dolphin morbillivirus (DMV) (Domingo et al. 1990, 1992, Barrett et al. 1995, Kennedy 1998, Di Guardo et al. 2005, Raga et al. 2008). In particular, the virus responsible for the 2006-2008 mortality episodes in pilot whales and striped dolphins shows a close genetic relatedness to the DMV strain causing the dramatic 
die-off that took place 15 yr before in the same area (Fernández et al. 2008, Raga et al. 2008, Van Bressem et al. 2009). Direct evidence of Morbillivirus infection has been recently reported in several striped dolphins, as well as in a pilot whale and a bottlenose dolphin Tursiops truncatus found stranded on the French Mediterranean coast (Keck et al. 2010).

\section{MATERIALS AND METHODS}

The present study reports the morpho-histopathologic, immunohistochemical, and biomolecular features of a case of morbilliviral encephalitis in a striped dolphin calf from Italy. On November 15, 2009, a $112 \mathrm{~cm}$, $16.8 \mathrm{~kg}$, condition code 1 (Geraci \& Lounsbury 2005) male striped dolphin calf was found dead, stranded on the Latium coast of Italy (Ostia Lido, 41 $44^{\prime} 15^{\prime \prime} \mathrm{N}$, $\left.12^{\circ} 16^{\prime} 57^{\prime \prime} \mathrm{W}\right)$. The animal was promptly submitted to post mortem examination, which was carried out by means of a standard necropsy protocol (Geraci \& Lounsbury 2005). Tissue samples collected included all major organs, adrenal glands, and lymph nodes (pulmonary, mediastinal, and mesenteric). Samples were fixed in $10 \%$ neutral buffered formalin, processed routinely, cut into $5 \mu \mathrm{m}$ thick sections, and subsequently stained with haematoxylin and eosin (H\&E).

Morbillivirus immunohistochemistry (IHC) was conducted on representative areas from the whole brain (telencephalon, diencephalon, mesencephalon, pons, cerebellum, medulla oblongata), lung, lymph nodes (pulmonary, mediastinal, and mesenteric), and spleen using a commercially available mouse monoclonal antibody against canine distemper virus (CDV) nucleoprotein (N) antigen (VMRD). This antibody recognizes the same epitope from different Morbillivirus genus members, including DMV. Morbillivirus-positive tissues from a CDV-infected dog (brain) and a DMVinfected striped dolphin (brain, lung, lymph nodes) were used, along with the pulmonary tissue from a Phocine (phocid) distemper virus (PDV)-infected common seal Phoca vitulina, as control tissues. As negative controls, uninfected striped dolphin tissues were utilized, together with tissues from known DMV-infected striped dolphins, but with omission of the primary antibody (Di Guardo et al. 2010).

Extracts from all the aforementioned tissues were submitted for reverse transcription-polymerase chain reaction (RT-PCR) that targets a highly conserved $\mathrm{N}$ gene fragment of 287 base pairs (Frisk et al. 1999). A virus neutralization assay for detecting anti-Morbillivirus (CDV) antibodies (Van Bressem et al. 2001), a rapid serum agglutination (RSA) test for anti-Brucella spp. antibodies (Randall et al. 2006), and a modified agglutination test (MAT) detecting anti-Toxoplasma gondii antibodies (Dubey et al. 2005) were performed on the serum. Bacteriological investigations were run on brain, liver, intestine, spleen, lung, kidney, and blood clots.

\section{RESULTS AND DISCUSSION}

Gross necropsy findings were limited to the respiratory, hepatobiliary, and digestive systems. In the lung, there was pulmonary congestion, multifocal consolidation, subpleural emphysema, and moderate catarrhal exudate within bronchial lumina. There was a diffuse hepatosis, with a light brown discoloration of the liver parenchyma. A chronic catarrhal enteritis was also apparent, with numerous Tetrabothrium forsteri cestodes filling the intestinal lumen. The stomach was devoid of contents.

Microscopic findings of note were seen affecting the nervous, respiratory, digestive, and hepatobiliary systems. The most significant histopathological changes were observed in the brain. There was a bilateral, subacute to chronic, non-suppurative meningoencephalitis, which was characterized by prominent lymphohistiocytic and plasmacellular perivascular cuffings, neuronal degeneration, microgliosis, astrocytosis, neuronophagia, and multinucleate synctia (Fig. 1). Affected regions of the brain included the cortical and subcortical forebrain (diencephalon and mesencephalon) and brainstem (pons and medulla oblongata), with no concurrent involvement of the cerebellar parenchyma.

In the bronchial and bronchiolo-alveolar lumina, there was a sero-mucinous exudate with interspersed macrophages. Additional pulmonary findings included a chronic lymphoid interstitial pneumonia with alveolar atelectasis and focal interstitial fibrosis. Hepatocytes from many liver lobules contained more or less abundant lipid vacuoles (steatosis). A severe catarrhal enteritis was found in the small intestine, where Peyer's patches showed lymphoid hyperplasia, and parasitic microgranulomas were also apparent within the submucosa and serosa. No additional microscopic changes were observed in any other tissue from the dolphin under study.

Morbillivirus IHC was positive exclusively from the brain tissue, with antigen detection in neuronal cell bodies, axons, dendrites and in the surrounding neuropil and, less commonly, in astrocytes (Fig. 2). Morbillivirus RT-PCR was also positive from several brain areas including the thalamus, mesencephalon, pons, and medulla oblongata, but negative from samples of cerebellum and all other tissues. Single, positively immunolabeled intranuclear inclusions were occasionally observed in neurons. A low neutralizing antibody titer 


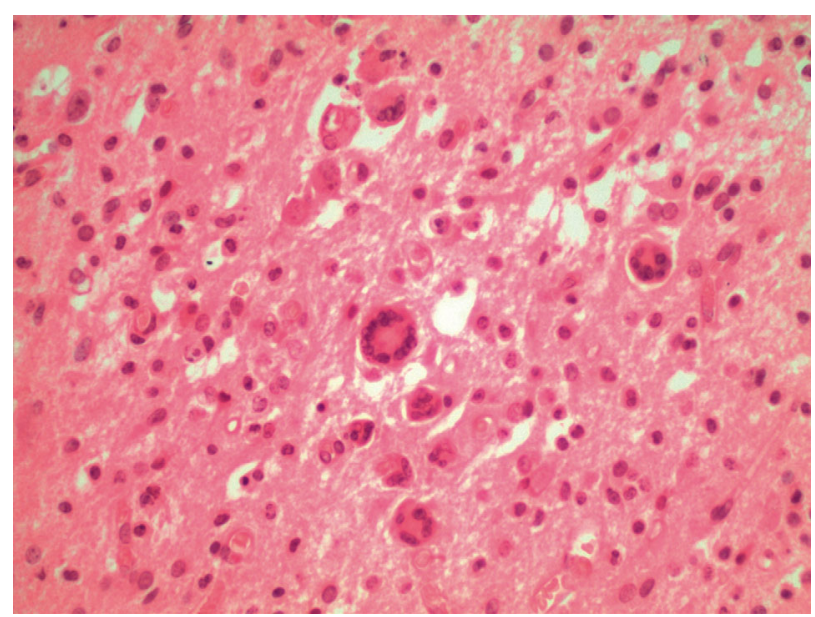

Fig. 1. Stenella coeruleoalba. Brain of a striped dolphin with morbilliviral encephalitis lesions. Evidence of multinucleate syncytia is shown in the thalamus. Haematoxylin and eosin staining (magnification 250x)

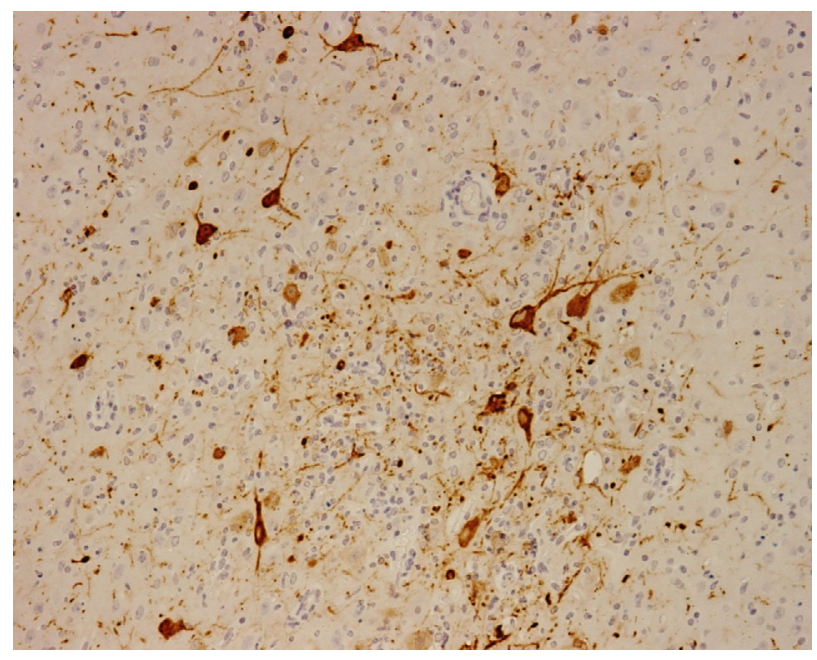

Fig. 2. Stenella coeruleoalba. Brain of a striped dolphin with morbilliviral encephalitis lesions. Large amounts of viral antigen are shown in cortical neuronal cell bodies and in the surrounding neuropil. Mayer's haematoxylin counter-staining (magnification 250×)

(1:10) against Morbillivirus (CDV) was found, while serological tests for Brucella spp. and Toxoplasma gondii were negative. All bacteriological investigations yielded no growth at $96 \mathrm{~h}$.

On the basis of the histopathological, IHC, RT-PCR, and serological findings, we conclude that morbilliviral encephalitis was the primary cause of this striped dolphin's death. Indeed, the severe inflammatory brain lesions, showing a bilateral and multifocal distribution, also involved the medulla oblongata. Among the grey matter nuclei located in this region, there is the 'dorsal motor nucleus of vagus nerve' (Summers et al. 1995), a brain structure crucially involved in the regulation of vital activities such as cardiac and respiratory functions. It is highly plausible that such grey matter nucleus was damaged in this dolphin calf, with subsequent death of the animal. Concurrent chronic and parasitic enteritis, along with moderate and diffuse hepatopathy, catarrhal bronchopneumonia, and lymphoid interstitial pneumonia, likely contributed to the demise of this cetacean. Associated findings of lymphoid interstitial pneumonia and catarrhal bronchopneumonia, similar to those reported herein, have recently been described in several striped dolphins beached off the Ligurian Sea coast of Italy, in which simultaneous evidence of parasitic bronchopneumonia due to the nematode Halocerchus lagenorhynchi was also apparent (Di Guardo et al. 2010). In contrast to these cases, however, no parasitic bodies were observed in the lung tissue from the animal under study.

Before the present case of morbilliviral encephalitis, which was presumably caused by DMV, direct evidence of Morbillivirus infection in the context of the 2006 to 2008 Mediterranean Sea epidemic had been reported, along the Italian coastline, only in one other striped dolphin found stranded in June 2007 on the northwestern coast of Sardinia (Appino et al. 2008). Furthermore, although a significant increase in striped dolphin mortality was observed along the Ligurian Sea coast of Italy (neighbouring the French coastline) during the second half of 2007 (F. Garibaldi \& W. Mignone pers. comm.), no IHC or RT-PCR evidence of Morbillivirus infection was detected in any of 8 striped dolphins stranded on the Ligurian coastline from August to December 2007, 4 of which had anti-Morbillivirus (CDV) neutralizing antibodies in their sera. Furthermore, a multifocal, severe, non-suppurative meningoencephalitis was observed in the remaining 4 dolphins, all seropositive to Toxoplasma gondii (and Morbillivirus-seronegative); 2 of these also showed IHC evidence of Toxoplasma gondii cysts and zoites in their brain (Di Guardo et al. 2010).

The main reason for concern associated with the case reported herein, as compared to the 'usual' phenotypic and biologic features of morbilliviral infection in cetaceans (Domingo et al. 1992, Kennedy 1998, Di Guardo et al. 2005, Van Bressem et al. 2009), is the fact that both IHC and RT-PCR evidence of Morbillivirus was 'restricted' to the brain, whereas the cerebellum and all other tissues from the dolphin studied appeared unaffected. Indeed, morbilliviruses are known to display in cetaceans - as in many other aquatic and terrestrial mammal species - a multi-organ tropism, with the lymphoid, pulmonary, brain, and epithelial tissues of the host being simultaneously involved in the pathogenesis of infection (Kennedy 1998, Di Guardo et al. 2005, Van Bressem et al. 2009). In this respect, we cannot entirely rule out the hypothesis that a number of 
extra-cerebral, Morbillivirus-associated lesions occurred at some stage in this dolphin, with subsequent resolution of such lesions in the course of infection. Nevertheless, the absence of IHC detection of morbilliviral antigen, coupled with the absolute lack of biomolecular (RT-PCR) evidence of the morbilliviral genome in all other tissues (including the cerebellum) from the animal, do not support the above assumption. Alternatively, we cannot exclude the additional possibility that a novel Morbillivirus strain with selective neurotropic activity infected this animal.

From the neuropathological standpoint, microgliosis and astrocytosis should be regarded, along with the presence of multinucleate syncytia, as histomorphologic characteristics clearly indicating a chronic brain lesion in the dolphin under study (Summers et al. 1995). As in the present case, morbilliviral infectionassociated pathology and presence of a morbilliviral antigen 'restricted' to the brain were previously reported in 6 striped dolphins beached off the coast of Spain after the 1990 to 1992 DMV epidemic. Those cases however, differently from the case described in the present study, involved adult animals that also exhibited a chronic morbilliviral encephalitis resembling subacute sclerosing panencephalitis (SSPE) in humans (Domingo et al. 1995), a disease condition which has a number of morphologic and pathogenetic features in common with old dog encephalitis (ODE) (Rima et al. 1987). Again, the brain from these 6 cetaceans showed no evidence of multinucleate syncytia, which are never seen in SSPE-affected patients (Cosby et al. 2002, Rima \& Duprex 2006) and in ODE-affected canines (Summers et al. 1995).

With special reference to the modalities through which morbilliviral infection was acquired, it seems reasonable to believe that close and repeated intraspecies/interspecies contacts between this dolphin and one or more infected cetaceans (calf-mother interactions, in particular) could represent a very plausible explanation (Domingo et al. 1992, Kennedy 1998, Di Guardo et al. 2005). Nonetheless, the chronic nature of brain lesions does also suggest that infection may have been transmitted to this very young animal through ingestion of maternal colostrum/milk, which has previously been indicated as a potential DMV excretion route (Domingo et al. 1992). Additionally, the possibility of transplacental infection occurrence should not be ruled out. To our knowledge, maternofaetal transmission of Morbillivirus (DMV) among freeranging cetaceans has been reported before only in a pilot whale foetus during the 2006 to 2008 Mediterranean Sea epidemic (Fernández et al. 2008).

Finally, we believe that the low neutralizing antibody titer (1:10) against Morbillivirus (CDV) could be in agreement, at least in principle, with the supposedly chronic evolution of the infection process in the dolphin studied. This finding, however, may have resulted either from virus-induced immune suppression (Domingo et al. 1992, Kennedy 1998, Di Guardo et al. 2005, Van Bressem et al. 2009) or from a negative interference exerted by colostral antibodies, if the calf's mother was infected by Morbillivirus. Undoubtedly, DMV or Porpoise morbillivirus (PMV), which are almost identical from a genomic and antigenic standpoint (Kennedy 1998, Di Guardo et al. 2005, Van Bressem et al. 2009), would have represented a more suitable option than CDV as the laboratory antigen(s) utilized in the virus neutralization assay for this study. As a consequence, we could have detected higher immunoglobulin titers in the calf's serum. Nevertheless, it should also be pointed out that CDV antigen has been widely used in sero-epidemiological surveys aimed at estimating the prevalence of morbilliviral infections in several freeranging pinniped (Duignan et al. 1994, 1995, 1997, Barrett et al. 1995) and cetacean (Barrett et al. 1995, Di Guardo et al. 1995, 2010, Di Francesco et al. 2010) species and populations worldwide.

Acknowledgements. This work, which is dedicated to the memory of Dr. Tom Barrett and Prof. Marco Pedone, was carried out with grants from Ministero dell'Ambiente e della Tutela del Territorio e del Mare in the framework of the research project Cause di Mortalità e Studi Patogenetici in Cetacei Spiaggiati sulle Coste Italiane, coordinated by G.D.G.

\section{LITERATURE CITED}

Appino S, Bollo E, Briguglio P, Rotta A and others (2008) Osservazioni su popolazioni di mammiferi marini in Sardegna e descrizione di un caso di infezione da Morbillivirus in un esemplare di stenella striata (Stenella coeruleoalba). Praxis Vet 29:2-6

Barrett T, Blixenkrone-Møller M, Di Guardo G, Domingo M and others (1995) Morbilliviruses in aquatic mammals: report on round table discussion. Vet Microbiol 44: 261-265

Cosby SL, Duprex WP, Hamill LA, Ludlow M, McQuaid S (2002) Approaches in the understanding of morbillivirus neurovirulence. J Neurovirol 8:85-90

Di Francesco CE, Marsilio F, Proietto U, Mignone W, Casalone C, Di Guardo G (2010) Anti-Morbillivirus antibodies in stranded striped dolphins (Stenella coeruleoalba): time and temperature dependent fluctuations. Aquat Mamm 36:294-297

> Di Guardo G, Agrimi U, Morelli L, Cardeti G, Terracciano G, Kennedy S (1995) Post mortem investigations on cetaceans found stranded on the coasts of Italy between 1990 and 1993. Vet Rec 136:439-442

> Di Guardo G, Marruchella G, Agrimi U, Kennedy S (2005) Morbillivirus infections in aquatic mammals: a brief overview. J Vet Med A 52:88-93

$>$ Di Guardo G, Proietto U, Di Francesco CE, Marsilio F and others (2010) Cerebral toxoplasmosis in striped dolphins (Stenella coeruleoalba) stranded along the Ligurian Sea coast of Italy. Vet Pathol 47:245-253 
Domingo M, Ferrer L, Pumarola M, Marco A and others (1990) Morbillivirus in dolphins. Nature 348:21

Domingo M, Visa J, Pumarola M, Marco AJ and others (1992) Pathologic and immunocytochemical studies of Morbillivirus infection in striped dolphins (Stenella coeruleoalba). Vet Pathol 29:1-10

Domingo M, Vilafranca M, Visa J, Prats N, Trudgett A, Visser I (1995) Evidence for chronic Morbillivirus infection in the Mediterranean striped dolphin (Stenella coeruleoalba). Vet Microbiol 44:229-239

Dubey JP, Fair PA, Bossart GD, Hill D and others (2005) Comparison of several serologic tests to detect antibodies to Toxoplasma gondii in naturally exposed bottlenose dolphins (Tursiops truncatus). J Parasitol 91: 1074-1081

Duignan PJ, Saliki JT, St. Aubin DJ, House JA, Geraci JR (1994) Neutralizing antibodies to phocine distemper virus in Atlantic walruses (Odobenus rosmarus rosmarus) from Arctic Canada. J Wildl Dis 30:90-94

Duignan PJ, Saliki JT, St. Aubin DJ, Early G and others (1995) Epizootiology of morbillivirus infection in North American harbor seals (Phoca vitulina) and gray seals (Halichoerus grypus). J Wildl Dis 31:491-501

Duignan PJ, Nielsen O, House C, Kovacs KM and others (1997) Epizootiology of morbillivirus infection in harp, hooded, and ringed seals from the Canadian Arctic and western Atlantic. J Wildl Dis 33:7-19

Fernández A, Esperón F, Herráez P, Espinoza de los Monteros A, and others (2008) Morbillivirus and pilot whale deaths, Mediterranean Sea. Emerg Infect Dis 14:792-794

Frisk AL, König M, Moritz A, Baumgärtner W (1999) Detection of distemper nucleoprotein RNA by reverse transcription-PCR using serum, whole blood, and cerebrospinal fluid from dogs with distemper. J Clin Microbiol 37: 3634-3643

Geraci JR, Lounsbury VJ (2005) Marine mammals ashore: a field guide for strandings, 2nd edn. National Aquarium in

Editorial responsibility: Michael Moore,

Woods Hole, Massachusetts, USA
Baltimore, Baltimore, MD

> González L, Patterson IA, Reid RJ, Foster G, and others (2002) Chronic meningoencephalitis associated with Brucella sp. infection in live-stranded striped dolphins (Stenella coeruleoalba). J Comp Pathol 126:147-152

> Hernández-Mora G, González-Barrientos R, Morales JA, Chaves-Olarte E, and others (2008) Neurobrucellosis in stranded dolphins, Costa Rica. Emerg Infect Dis 14: 1430-1433

Keck N, Kwialek O, Dhermain F, Dupraz F, and others (2010) Resurgence of Morbillivirus infection in Mediterranean dolphins off the French coast. Vet Rec 166:654-655

> Kennedy S (1998) Morbillivirus infections in aquatic mammals. J Comp Pathol 119:201-225

Raga JA, Banyard A, Domingo M, Corteyn M, and others (2008) Dolphin morbillivirus epizootic resurgence, Mediterranean Sea. Emerg Infect Dis 14:471-473

Randall LZ, Jeremiah TS, Alastair PM, Simon DB and others (2006) Serological survey for Brucella spp., phocid herpesvirus-1, phocid herpesvirus-2, and phocine distemper virus in harbour seals from Alaska, 1976-1999. J Wildl Dis 42:290-300

Rima BK, Baczko K, Imagawa DT, ter Meulen V (1987) Humoral immune response in dogs with old dog encephalitis and chronic distemper meningo-encephalitis. J Gen Virol 68:1723-1735

> Rima BK, Duprex WP (2006) Morbilliviruses and human disease. J Pathol 208:199-214

Summers BA, Cummings JF, de Lahunta A (1995) Veterinary neuropathology, 1st edn. Mosby, St Louis, MO

Van Bressem MF, Waerebeek KV, Jepson PD, Raga JA and others (2001) An insight into the epidemiology of dolphin morbillivirus worldwide. Vet Microbiol 81:287-304

> Van Bressem MF, Raga JA, Di Guardo G, Jepson PD, and others (2009) Emerging infectious diseases in cetaceans worldwide and the possible role of environmental stressors. Dis Aquat Org 86:143-157

Submitted: January 3, 2011; Accepted: March 7, 2011

Proofs received from author(s): May 20, 2011 